\title{
Watt, Bob, UK Election Law: a critical examina- tion, UK, Glass house press, 2006, 264 pp.
}

El profesor Watt es un jurista de la Universidad de Essex en el Reino Unido, y autor de diversos textos enfocados en las votaciones. Este libro que se reseña presenta el aspecto ideológico de las elecciones en el Reino Unido haciendo un repaso histórico y de contexto para entender la relación entre la teoría democrática y el mercado electoral, en palabras del propio Watt.

La historia electoral del Reino Unido data de siglos, ya que por su particular modo de elegir las autoridades y de los respectivos estamentos sociales, impactan en cómo en el imaginario colectivo británico la perspectiva electoral fue evolucionando hasta permitir romper con el bipartidismo clásico a un multipardismo. ${ }^{1}$

El libro se divide en ocho partes: I)Law, Public Policy and Ideology, II)The Right to vote, III) The mecanismo of voting, IV) The nomination of a Candidate, V) Election Expenses, VI) Challenging the result of an election, VII) The problema and a Possible Solution, VIII) The immediate Future.

1 Para este punto recomendamos la obra del profesor Paul Webb, The Modern British Party System, UK, Sage Pub, 2000.

Otra interesante obra acerca de la política del Reino Unido es: The Oxford and book of British Politics, UK, OUP, 2009. 
La obra del profesor Watt está basada en documentos históricos que reflejan una profunda investigación así como de reflexión acerca de la problemática electoral en la era de los medios de comunicación.

\section{Chapter 1: Law, Public Policy and Ideology}

La principal propuesta de este apartado es constatar que la Ley Electoral no es un instrumento legal de carácter neutro, está diseñada según el profesor Watt para controlar una franquicia en dos dimensiones:

si nos fijamos primero en la amplitud de la franquicia, podemos ver que fue disputada desde la Edad Media. Desde los tiempos de los normandos hasta el comienzo del siglo XX había dos formas básicas de la franquicia electoral de la ciudad y del condado. Las franquicias de la ciudad se concedieron de forma compleja a habitantes de las ciudades, pero la franquicia del condado era originalmente ejercidos por todos los propietarios libres, del sexo masculino que habitaran en el condado. ${ }^{2}$

\section{Chapter 2: The right to vote}

Este capítulo contiene un análisis del derecho al voto, inicia con las reflexiones hechas como voto particular de Holt Cj's en el juicio Ashby vs. White. Este punto de vista contrario al de la mayoría de la "The Court of Common Pleas" cuyo punto de vista fue confirmado en "The House of Lords" y con fallo en contra en "House of Commons". El desarrollo del derecho al voto fue influenciado de manera contundente al ser considerado como una franquicia más que como un derecho, este punto de vista ayuda a analizar el sentido de la idea democrática en el Reino Unido. Este autor sugiere la naturaleza del derecho al voto a la luz de la legislación británica así como en los tratados internacionales de derechos humanos suscritos con anterio-

2 El sistema electoral inglés es paradigmático, conocido como de mayoría/pluralidad, teniendo como consecuencias las siguientes: después de que los votos han sido emitidos y contados, los candidatos o partidos que obtuvieron una mayor cantidad de votos son declarados ganadores, existen cinco variantes de este sistema: mayoría simple, voto de bloque, voto en bloque por partido, voto alternativo y doble ronda.

Los países allegados históricamente y políticamente al Reino Unido: Canadá, Estados Unidos y la India. Reynolds, Reilly y Ellis, Diseño de sistemas electorales: el nuevo manual de IDEA International, México, TEPJF-IFE-IDEA, 2006. 
ridad. Este capítulo se apoya en el desarrollo teórico de John Stuart Mill, quien explica la importancia del derecho al voto así como su perspectiva al futuro para la población.

\section{Chapter III: The mecanism of voting}

Este apartado está íntimamente ligado con el capítulo antecesor, ya que plantea el estudio del mecanismo del voto y su evolución histórica en el Reino Unido y cómo el presente sistema de votación ha podido contribuir a caer, con sus diversas formas del método de voto (postal, balotaje, voto electrónico) y apoyado por partidos políticos que han diseñado políticas para remediar la baja participación política de los ciudadanos y generar la afiliación partidista. La compra del voto es un tema que también es documentado a través de las diversas legislaciones y otros documentos legislativos que comprueban los actos de corrupción en materia de las elecciones. Tanto el segundo y tercer capítulo hacen énfasis en la importancia del "derecho al voto" y de su ejercicio, así el cambio de concepción de esta actividad cívica a una responsabilidad de tomar parte en la formación del gobierno.

\section{Chapter IV: The Nomination of a Candidate}

Para este apartado el profesor Watt nos ilustra con una problemática que provocaba la confusión de los electores y que el gobierno británico corrigió con una reforma que preveía evitar que los términos electorales se confundieran a la hora de elegir partidos y candidatos (The Registration of Political Parties Act 1998). A juicio del jurista de Essex, esta ley y de la Political Parties, Elections and Referendums Act 2000, vinieron a generar una concentración del poder en las elites partidistas, rezagando a la disidencia partidista y aglutinando la fuerza del partido en la cúpula, además de permitir un proceso de concebir al partido como una marca comercial. Esto altera, a juicio de Bob Watt, el sentido democrático de ejercicio del derecho de voto. ${ }^{3}$

3 Atendiendo a esta perspectiva que ofrece el profesor Watt, los derechos políticos suelen designarse como aquellos derechos fundamentales que tienen como finalidad proteger la participación de los ciudadanos en la gestión de los asuntos públicos, y en consecuencia están más inmediatamente relacionados con el funcionamiento de las instituciones democráticas. El profesor español Diez-Picazo, explica que los derechos 


\section{Chapter V: Election Expenses}

En este capítulo, el profesor Watt ofrece una reflexión bastante interesante acerca de la competencia electoral en el Reino Unido y lo contrasta con casos en los que esta peculiar característica británica es puesta en duda: $\mathrm{R} v$ s. Jones, $\mathrm{R}$ vs. Whicher, a juicio de Watt este comportamiento irregular es causado por la tendencia de los partidos políticos a convertirse en "productos comerciales", si es válida la comparación el jurista de Essex es severo en su juicio, denota la influencia republicana de sus argumentos. Uno de los dilemas más importantes en las elecciones es el financiamiento y los gastos de campaña; la crítica del profesor Watt es la preponderancia de este modelo de mercado que ha cambiado la lógica de los procesos electorales contemporáneos.

La publicidad y la exposición mediática de los políticos han planteado dejar a un lado los proyectos por simples pautas publicitarias. ${ }^{4}$

\section{Chapter VI: Challenging the Result of an Election}

En este apartado se puso a prueba al sistema de recursos electorales británico a juicio del profesor Watt, la impugnación de los resultados electorales, es casi totalmente en manos de los partidos políticos a pesar de la disposición legal que indica que estos recursos deben ser impugnados por la ciudadanía. Además, la jurisprudencia revela que hay una deferencia judicial que funciona, en el mejor de los casos, en favor de la burocracia electoral y en el peor de los casos, el jurista de Es-

políticos no sólo están para proteger el correcto funcionamiento de la democracia, sino que estaban también al servicio de otros valores.

Para Diez-Picazo: "Estos derechos fundamentales son, los que en la tradición del constitucionalismo han sido siempre vistos como propios únicamente de los ciudadanos, los derechos políticos".

Cfr. Diez-Picazo, Luis María, Sistema de derechos fundamentales, México, 3a. ed., Civitas-Thomson, 2008.

4 No sólo en ámbito político británico, el profesor Stefan Marschall hace un análisis exhaustivo de las implicaciones en los medios de comunicación en el sistema político alemán, él la califica como "Mediedemokratie", ya que los medios de comunicación han influido en la manera en que la política se ha conceptualizado y una nueva forma de Estado además de una creciente concentración de los medios de comunicación en Alemania. Stefan, Marschall, Das Politische System Deutschlands, UVK, Verlangs, 2007. 
sex nos da a saber que el proceso electoral no es totalmente confiable y presenta constantes irregularidades.

\section{Chapter VII: The Problem and Posible Solution}

Uno de los planteamientos que hace esta obra, es cercana a la lógica del derecho de índole continental, y es considerar a los derechos políticos como derechos humanos, basándose en los tratados en ámbito europeo de derechos humanos y en la jurisprudencia de la Corte Europea.

Además de una tendencia, también de índole continental, de resolver los problemas del ámbito político en la justicia o como se le llama en la doctrina latinoamericana "la judicialización de la politica". ${ }^{5}$

La notoria influencia del derecho continental es evidente en la propuesta de resolución de la problemática británica, la evolución del paradigma de los derechos humanos hace que la perspectiva de la impartición de justicia se amolde a los estándares de esta perspectiva.

Las implicaciones en el ámbito de derechos políticos como derecho humanos son un tópico de carácter trascendente para la Corte Europea de Derechos Humanos: "Turquía vs. El partido del Pueblo", "Castells vs. Reino España", "Herri Batasauna vs. Reino de España", etcétera.

\section{Chapter VIII: The Immediate Future}

En este último apartado, el profesor Watt analiza la importante decisión emitida por la Comisión Electoral, concerniente al funcionamiento del sistema de votación postal y su susceptibilidad de corromperse, así como el análisis de un comunicado emitido por la comisión electoral en donde expone las medidas de seguridad que se llevan a cabo en las elecciones.

5 En las democracias, la justicia electoral juega un decisivo rol para asegurar la estabilidad del sistema político y su adhesión al marco constitucional y legal y contribuye a la consolidación del gobierno democrático. El rol trascendental de la justicia electoral no es nuevo, ha sido reconocido como un factor crucial ya sea en las democracias establecidas como en las emergentes.

Cfr. Orozco-Henríquez, Ayoub y Ellis, Electoral Justice: The International IDEA Handbook, Sweden, 2010. 
En este capítulo se muestra una de las diversas irregularidades en el proceso electoral británico. El profesor Watt es enfático en hacer públicos estos sucesos, así como denunciar el control partidista que tienen las élites de los órganos electorales. Las implicaciones de la propuesta que hace ese libro es revalorizar una obligación, reconocida en el ámbito europeo por diversos tratados internacionales y por el Tribunal Europeo de Derechos Humanos.

La perspectiva del profesor Watt es crítica y a la vez propositiva con respecto a las posibles soluciones a los problemas electorales, así como el apego a los tratados internacionales en materia de derechos humanos celebrados por el Reino Unido, además de una perspectiva republicana de los derechos políticos. El libro es una excelente referencia para comprender el interesante contexto político británico.

Gonzalo Farrera Bravo

Instituto de Investigaciones Jurídicas de la UNAM 